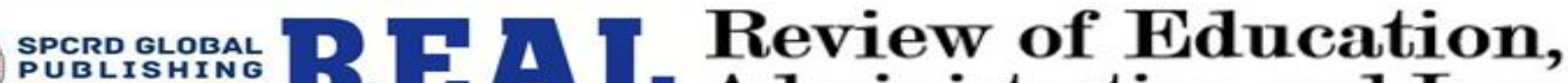 Administration and Law \\ Journal homepage: http://real.spcrd.org ISSN (Print): 2708-1788 \\ ISSN (Online): 2708-3667
}

\section{Formative Assessment Practices in Federal Government Schools: Issues and Problems}

\author{
${ }^{a}$ Muhammad Akram Shakir, ${ }^{\mathrm{b}}$ Rabia Bahoo, ${ }^{\mathrm{c}}$ Musarrat Jahan, ${ }^{\mathrm{d}}$ Muhammad Latif Javed \\ a Principal, FG Public School (Girls) Kharian Cantt, Pakistan \\ Email: raza_akram20o9@yahoo.com \\ ${ }^{\mathrm{b}}$ Lecturer, The Govt. Sadiq College for Women University Bahawalpur, Pakistan \\ Email: rabia.bahoo@gscwu.edu.pk \\ ${ }^{c}$ Assistant Professor, Department of Special Education, The Islamia University of Bahawalpur, Pakistan \\ Email: m.jahan99@yahoo.com \\ ${ }^{\mathrm{d}}$ Assistant Professor, Department of Education, The Islamia University of Bahawalpur, Bahawalnagar Campus, \\ Pakistan \\ Email: latif.javed@iub.edu.pk
}

\begin{tabular}{l} 
ARTICLE DETAILS \\
\hline History: \\
Accepted o7 March 2021 \\
Available Online $31^{\text {st }}$ March 2021
\end{tabular}

\section{ABSTRACT}

Assessment is the key element of teaching learning process in schools. Formative assessment is generally accepted as a valuable component of teachers' classroom assessment strategies. The study intends to explore the level of association of formative assessment with academic

\section{Keywords:}

Formative Assessment, Federal

Government Educational

Institutions (Fgeis) Cantt/

Garrison, Practices and Issues

JEL Classification:

I21, $P_{3} 6$

DOI: $10.47067 /$ real.v4i1.114 performance of secondary school students and to analyze the practices of formative assessment in schools. The study was descriptive in nature. The focus group interviews and observation techniques were used to gather information regarding academic, social, emotional, and cultural activities of students in schools. The population of the study comprises over all the principals, teachers and students of FGEIs of Lahore region. Sample was drawn by using simple random technique. The findings of the study revealed that teachers don't have enough knowledge about formative assessment but they possess appropriate understanding of summative assessment. Replication of test is the exclusive kind of assessment for improvement of different learning skills of students. It was recommended that authorities may develop and execute some plan to train and give awareness to the administration and teaching staff about the use and importance of formative assessment during teachinglearning process in schools.

(C) 2021 The authors. Published by SPCRD Global Publishing. This is an open access article under the Creative Commons Attribution-Non

Commercial 4.0

Corresponding author's email address: raza_akram2009@yahoo.com

\section{Introduction}

This is an era of technological and globalization. The quick and exclusively modernization in technology and globalization have influenced the school education. The testing and assessment are the 
back bone of the whole teaching learning process. These alterations in the evaluation system have made the world multitudinous about educational outcomes but the competency and acquisition of participants may not be accurate and sufficient any more (Hoskins \& Frederickson, 2008). In order to cope up with new challenges, principals and teachers are needed to be skilled with independent acquisition of knowledge and competencies about evaluation system in general and specifically the assessment in classrooms.

According to Lodhi and Kazi (2017) the definition and terminology of assessment is also used in place of evaluation, judgment, measurement, appraisal and review. The scope of assessment is expanded in every walk of life. Doctors, Engineers, Shop keepers and teachers also use measurement and assessment tool for achievement. In addition to that a researcher also assesses the quality of the research work. A bunch of studies have been conducted in order to investigate the potential of formative assessment for fulfilling these requisitions (Clark \& $\mathrm{Li}, 2013$; OECD, 2005, 2008). It was recognized that comparison of reference and primary level information leads towards formative assessment. This type of information latterly is adopted to bridge the gap. Both the teacher and taught analyze students' work and acquiring skills with learning objectives in formative assessment. Both can disseminate feedback about effectiveness and successfully achievement. The teacher plays a leading role in making decision about narrowing the gap due to possessing excessive knowledge. Whereas the student has a responsibility to appropriately accommodate the acquired information for fulfilling the gap (Arbaugh, \&Innes, 2008).

It was defined by Black and William, (2008) that assessment widely encompasses all educational activities which are utilized for collecting information's. Subsequently, the information are undertaken for the improvement and amendment of teaching and learning process. This interpretation speaks that assessment encompasses periodical group debate and dialogue and evaluation of taught assignment, class work and class assessment. The teaching learning strategies which bridge the needs and requirements of students are recognized as formative assessment. When and wherever students' progress and weaknesses are diagnosed by the concerned teachers, this type of information is used for amendment and betterment. All such strategies can guide to enhance students' success. (Sawyer, Graham, and Harris, 2002)

Successful assessment is also required for answers of critical questions. Is the mechanism of instructional work is continuously going well? Is progress carried out by the students measured by the school and teachers? Can schools and teachers point out and sketch out educational needs and response to them? (Sedler,2005). Tests and examinations are teaching learning tools for evaluating the progress of students. These are also traditional elements of numerically judging academic achievement and are necessary to make answerability for the institutions and the quality of education. The exclusively concrete type of digging out progress is famous as "summative assessment" which is tool and source of feedback for both parents and employers (Sedler,2005).

This is an established fact that in teaching learning process, assessement remained as a tool to valued the teacher's efforts towards teaching as well as the students' achievement to measured. This process of judging students performance also guide the teacher and administration to repaln and develop new targets in effective and efecient manners. In this way formative assessment is plays an important role in the teaching learning process, before its end where returen to take corrective measures may not be possible. The following main objectives of the study are to study the process of formative assessment in schools and to analyse the issues and roblems in formative assessment process 
in schools.

To achieve the objectives of the study, following research question were framed to examine the situation.

1. What are the ongoing formative assessment practices and issues in $\mathrm{FGEI}(\mathrm{C} / \mathrm{G})$ schools?

2. How do teachers have awareness about formative assessment?

3. Is there the Relationship between formative assessment with academic achievements of secondary school students?

\section{Review of Literature}

The renowned psychologists and educationists Bloom and Hastings firstly introduced the term 'Formative Assessment" in educational scenario. It is defined as the feedback and correctives communicated to both teacher and taught.Black and William (2008) also revealed the significance of formative assessment in their research work.William and Thompson (2008) mentioned five strategies for practicing formative assessment in teaching learning process. (1) Identifying criteria for success. (2) Formulating exclussive classroom discussion. (3) Motivating learners for academic, inspirational and educational resources (4) Provision of feedback for forwarding to the students (5) Stimulating the learners for acquisition ( William \& Thompson, 2008) .

McMillan (2003) suggested that high-stake testing and classroom practices were a few elements ensuring the assessment decision making of the educators. The retrospective phrases and sentences are just part and parcel of the story but there is a truly situation which may be the effective assessment such as formative assessment. Its main objective is to locate and make response to students' intellectual requirements. In simulative learning environment, educator use strategies which include formative assessment and periodical assessments of student comprehension. It is favourable for teachers to conduct their teaching strategies according to the needs of their students and it also helps the students to obtain elevated milestones of their progress.

Teachers also exclusively engage students in the teaching learning mechanism, making support them to master competency that is helpful for better learning. The implementation of formative assessment during teaching learning processes in Pakistan is very challenging. A few hurdles and impediment with regard to formative assessment practices have been popped up in this context. Teaching learners how to acquire is the prime aim of the formative assessment. The class teachers need to educate to test for ensuring students excellent performance in summative assessments (Black, 2015; Careless, 2012; Yin \& Buck, 2015). In addition to that all previous researches concerning formative assessment practices focuses on issues in foreign or unearth barriers to make implement in this region. There is least interest in a vast range of challenges combated by formative assessment practice in Pakistan. To bridge this gap, this work aims to explore issues and problems related to assessment in FGEI.

The problem under investigation was to conduct the study on formative assessment practices, issues and problems in FGEI (Cantt /Garrison) for boys Lahore cantonment. The literature review and findings are exclusively predicted to assist policymakers, administration and researchers to point out solutions effectively promulgation of formative assessment in the entire academic settings. 


\section{Research Methodology}

Study was descriptive in nature; survey method and observation technique were used to collect data. Population of the study comprises over all the principals, teachers and students of FGEIs of Lahore region. Sample was drawn by using simple random technique. In this way, o7 principals, 40 teachers and 200 students who were studying in $10^{\text {th }}$ class in FG (cantonment/garrisons) Boys Secondary School Lahore cantt. were selected through purposively sub type of Homogeneous sample technique. A purposive sampling is used when a researcher selects a sample based on their knowledge about the study and population.

\subsection{Method of Collecting Information}

The research questions were developed as exploratory in nature, because aim was to investigate different assessment techniques used by teachers. However, the ultimate goal of raising these questions were to think of assessment as something that should improve student s' learning and while collecting information, researcher looked for specific indication of assessment for learning. For this purpose, researcher thought of these questions as exploratory.

The process of information collection started as clear patterns of assessment development, observation notes, questions and other inquiries which include checking note books. In order to investigate these questions, the researcher conducted interview with all class teachers. The researcher also conducted structured observation of each participating class room and look at examples of assignments. During class room observation, the researcher took notes writing down every instance which the teacher was giving any type of verbal feedback to students or that of students giving feedback to each other.

Interview was also conducted after classroom observations. The assignments of students were also studied in order to get clarification for teachers and students. Table No 1 reflects that there are seven (07) Boys schools in Lahore region. All principals were included in the sample of the study. Only those teachers were selected who were teaching at secondary level.

Table 1: Selection of sample in quantitative form

\begin{tabular}{|l|l|l|l|l|l|}
\hline Sr.No. & School & Principal & Teachers & Students & Total \\
\hline 01 & FG B H/S No-A Lahore Cantt & 01 & 06 & 30 & 037 \\
\hline 02 & FG B H/S No-B Lahore Cantt & 01 & 06 & 30 & 037 \\
\hline 03 & FG B H/S No-C Lahore Cantt & 01 & 06 & 30 & 037 \\
\hline o4 & FG B H/S No - D Lahore Cantt & 01 & 06 & 30 & 037 \\
\hline 05 & FG M H/S No -E Lahore Cantt & 01 & 06 & 30 & 037 \\
\hline o6 & FG P/S No - F Lahore Cantt & 01 & 05 & 25 & 031 \\
\hline o7 & FG F P H/S No- G Lahore Cantt & 01 & 05 & 25 & 031 \\
\hline oo & Total Strength & $\mathbf{0 7}$ & $\mathbf{4 0}$ & $\mathbf{2 0 0}$ & $\mathbf{2 4 7}$ \\
\hline
\end{tabular}




\subsection{Observation Schedule for Students}

The following indicators and parameters were kept in mind while the observation of the study. Observation is the act of recognizing and noting facts or occurrences. No questions are asked in data collection. Only current behaviors of a person or group of persons in natural environment are observed. There was structured observation which is used when the research problem has been formulated precisely and observers have been told what is to be observed.

The researcher observed during the teaching learning process in the classroom for half an hour for each class. Group and student discussions during teaching learning in the classroom, teacher work which was assigned in the classroom as well as homework to ensure the prevailing understanding level of students as corrective measures were exclusively observed. Abrupt feedback was also managed for forthwith improvement of teaching learning process. The technique and strategies of student self- and peer-assessment were also administered on the spot. These are all practices, not instruments. There is no magic test or tool. Unfortunately, because of the accountability-saturated environment, we may have left a few good teaching and assessment practices behind along with some children.

\subsection{Methods for Analyzing data}

During analyzing, the researcher was looking for these elements of assessment for learning i.e. presence of rich questioning, teachers' comments on students' progress, a grade or praise, quality of self and peer assessment by students, quality of class room discussion, frequency of tests. Classroom observations notes were analyzed for any evidence of assessment. Mostly teachers during their focus group discussion reflected that for English class at secondary level, formative assessment was done through oral and written tests. Feedback to any pupil should be about the particular qualities of his or her work, with advice on what they can do to improve, and should avoid comparisons to other pupils. Data for this study was collected as part of a survey of 07 principals and 40 high school teachers' assessment practices and 200 students studying in FG (Cantt \Garrison) for boys Secondary Schools in Lahore cantt.

\section{Results and Discussion}

After the process of data analysis the following results were drawn;

\subsection{Findings from Principals' Interview}

Structured interview method was conducted to collect information about the subject purpose. A principal said "students are observed regularly during teaching learn in process. Class teachers provide an opportunity to the student to express their comprehension level skill through formative assessment techniques." Principal - B highlighted "teachers use a variety of techniques such as group discussion, peer learning, dialogue, debate and discussion for the purpose of feedback and improvement of the teaching and learning process. Principal - C pointed out "there is established formative assessment mechanism in our educational set up for improvement of teaching learning process.” Principal- D revealed "mostly teachers are well aware and cognizant of terminology formative assessment. There is also mechanism of teacher training programme. Teachers are given opportunity for in-service training. They are imparted pedagogical skills. This training program envelops academic, scholastic, professional, departmental as well as pedagogical skills. Accordingly, teachers are motivated and inspired to use all assessment techniques during the instructional work in order to develop 
performance of both teacher and taught.”

- The students are bestowed an opportunity to reflect their understanding during teaching learning. This interaction is initiated through formative assessment aids learning.

- There is also management of dialogue between pupils and teachers which is deemed thoughtful and reflective for expressing their ideas. These dialogues exclusively focus upon understanding level.

- Feedback mechanism is established and maintained as per the specific qualities of the students. This feedback may be able to enhance and develop teaching learning in the classroom.

- The performance of the students is determined and judged through formative assessment which is to be effective, favorable and productive. Subsequently the pupils are tamed in self-assessment which is helpful in understanding the main purpose of their learning.

\subsection{The Finding from teachers' Interview}

A focus group interview to retrieve information regarding the assessment technique used in the classroom was carried out in the selected schools of $\operatorname{FGEI}(\mathrm{C} / \mathrm{G})$ Lahore Region. Statements and quotes of individual participants are mirrored here. A group of teachers reflected 'we have been imparted inservice training during teacher training workshops. We stride to best to reflect acquire pedagogical skills during teaching learning process in the classrooms. Another group of teachers expressed their views 'students' revealed that there is close relationship between formative assessment practices utilized in class and academic achievement."

Group of secondary school teachers who were teaching to the secondary classes at Lahore reflected their view "there are different types of assessment which are utilized in the class room. Only one technique is not sufficient for learning achievement."

A group of English teachers highlighted their views about formative assessment "language is judged through oral tests, and translation method is also utilized for English language.”

\subsection{Formative Assessment Practices}

1- We differentiate the students with regard to their mental level and their attitude towards class work.

2- There is a specific performance standard level at our schools.

3- There is a strong relationship between formative assessment and students, achievement.

4- All the teachers are professionally trained and well aware about the knowledge of formative and summative assessment.

5- Just summative assessment is not sufficient for transfer of learning.

6- Only translation skill is judged in tradition through formative assessment.

7- There is significant difference in all these assessments.

8- For English class at secondary level, formative assessment is done through oral and written tests. Assessment practices are always according to needs of the students and match the mental level of the students, like the knowledge, vocabulary, skills.

\subsection{Discussion}

The prime aim of this research study was to explore formative assessment practices, issues and problems in federal government educational institutions (c/g) for Boys Lahore cantt. The finding and literature of previous research work focused on multipronged aspects of formative assessment issues at 
national and international level. Hoskins and Fredriksson (2008) pointed out that the existing skills and abilities of learners may not be appropriate and sufficient any more. In order to cope up with new challenges, new learners are needed to be skilled with independent acquisitions and competencies. Black, Careless, Yin and Buck, (2015) pointed out in their research that the class teachers need to educate to test for ensuring students excellent performance in summative assessments.

The problem under investigation was to conduct the study on formative assessment practices, issues and problems in FGEI (Cantt/Garrison) for boys Lahore cantt. The literature review and findings are exclusively predicted to assist policymakers, administration and researchers to point out solutions effectively promulgation of formative assessment in entire the academic settings.

The finding retrieved from the interview of principals conducted for current research work revealed that the performance of the students is determined and judged through formative assessment which is to be effective, favourable and productive. Subsequently the pupils are tamed in selfassessment which is helpful in understanding the main purpose of their learning. There is a strong relationship between formative assessment and students, achievement. Literature and finding surrounding to teachers focus group interview discussed and expressed that all the teachers are professionally trained and well aware about the knowledge of formative and summative assessment.

Just summative assessment is not sufficient for transfer of learning. Only translation skill is judged in tradition through formative assessment. There is significant difference in all these assessments. Findings retrieved from existing research study bridge the gap between previous research and present statement of the problem.

\section{Conclusions}

It was concluded that students assessed by formative assessment had significantly higher score/ranker than students who were not assessed. Teachers teaching secondary classes have to some extent concept / knowledge of formative and summative assessment. This also revealed that the main issue and problems regarding formative assessment was the lack of awareness and even some have little knowledge the way they use without appropriate training. The monitoring and evaluation system of the school administration this formative assessment also remained in question. On the basis of findings of the study, the following recommendations have been incorporated for the improvement in the field of formative assessment as well as improve the quality in education:

- Management of educational institutions may arrange the capacity building programs for teachers to introduce the formative assessment and ensure its proper implementation in the context of teaching and learning.

- The formative assessment may be incorporated in the National Education Policy and the National Curriculum accordingly.

- Frequent use of Formative assessment may be ensured at classroom level.

- The policy and effective tools for the implementation of formative assessment may be designed.

- Assessment experts may be called in at these institutions 


\section{References}

Arbaugh, J. B. (2008). Developing a community of inquiry instrument: Testing a measuring of the community of inquiry framework using a multi-institutional sample. The internet and Higher education, 11, 133-136.

Black, P. W. (2008). Assessment and classroom learning -. Assessment in education(5), 7-74.

Black, P. (2015). Formative assessment - an optimistic but incomplete vision. Assessment in Education: $\begin{array}{lllll}\text { Principles, } & \text { Policy } \quad \text { P } & \text { Practice, } & \text { 22(February), }\end{array}$ https://doi.org/10.1080/o969594X.2014.999643

Bloom, B. S., Hastings, J. T., \& Madaus, G. F. (1971). Handbook on formative and summative evaluation of student learning. Techniques. New York: McGraw-Hill. Retrieved from http://eric.ed.gov/ERICWebPortal/search/detailmini.jsp?_nfpb=true\&_\&ERICExtSearch_Search Value_o=EDo49304\&ERICExtSearch_SearchType_o=no\&accno=EDo49304

Clark, I., \& Li, M. (2013). Efficacy of Formative Classroom Assessments in Theory and Practice. College of Education. University of Washington.

Fontana, D. F. (2004). Improvements in Mathematics performance as a consequence of self assessment in portiguise primary schools pupils. British Journal of Educational Psychology., 63(3), 407-417.

Hoskins, B., \& Fredriksson, U. (2008). Learning to Learn: What is it and can it be measured. Joint Research Centre Technical Report JRC.

Mohammad, N., Lodhi S.M \& Kazi A.S., (2017). Role of Formative Assessment in the Improvement of the Process of Teaching and Learning: at Higher Education in Sindh, Pakistan Journal of Arts and Social Sciences 4 (2), 2-10.

McCurdy, B. S. (2002). A measurement in reading among students with learning disabilities.Comparison of teacher peer and self monitoring with curriculum based. Tpecial Educationhe Journal of S, 26(2), 162-180.

S. \& Haris, K. G. (1992). Direct teaching strategy instruction and strategy instuction with explicit self regulation : Effects on the composition skills and self efficasy of students with learning disabilities. Jnal of educational psychologyour, 84(3), 340.

Sedler, D. (2005). I of criteria - based assessment nterpretations and grading in higher education. Assessment \& Evaluation in Higher Education, 30(2), 175-194.

Wiliam, D., \& Thompson, M. (2008). Intergrating assessment with learning: What will it take to make it work? In C. A. Dweyer (Ed.), The future of assessment: Shaping teaching and learning (pp. 5382). New York: Erlbaum. 